Palavras chave: Pinheiro-do-Paraná Afilamento do tronco Análise de tronco

Histórico: Recebido 27/10/201 I Aceito 19/1 1/2013

Keywords: Araucaria Stem taper Stem analysis

Correspondência: afonso.figueiredo@pq.cnpq.br

\section{DINÂMICA DO AFILAMENTO DO TRONCO E DA PRODUÇÃO DE MADEIRA EM PLANTIOS DE Araucaria angustifolia}

RESUMO: A pesquisa objetivou avaliar a evolução da forma e do sortimento em plantios de Araucaria angustifolia. Os dados provieram de 30 árvores amostradas em plantios estabelecidos entre as décadas de 1940-1960 na Floresta Nacional de Irati, Paraná. As árvores foram submetidas à técnica de análise de tronco completa que permite a reconstituição de todo o crescimento passado. Os dados gerados possibilitaram a obtenção de diâmetros às diferentes alturas e nas várias idades de cada árvore. $\bigcirc$ perfil médio por idade foi gerado com funções de afilamento e funções splines cúbicas foram usadas para determinar a dinâmica do sortimento por classe de idade. Também foram realizados estudos sobre a evolução da forma do tronco com fatores de forma. Os resultados foram apresentados com a média de todas as árvores e agrupando-as em duas classes de sítio e indicam que aos 50 anos as árvores atingem um volume médio del,20 $\mathrm{m}^{3}$, dos quais, I4\% poderia ser utilizado para laminação, 66,2\% para serraria 2, 15,9\% para serraria I, $3,7 \%$ para celulose e $0,3 \%$ destinados para resíduos. Nessa mesma idade, os sítios I e II apresentaram volume total médio de $1,94 \mathrm{~m}^{3}$ e $0,57 \mathrm{~m}^{3}$, respectivamente. O Polinômio de $5^{\circ}$ grau ajustado para as classes de idade indicou que a forma do tronco melhora com a idade, tornando-os mais cilíndricos. Essa mesma tendência pode ser constatada com o fator de forma, o qual, praticamente, estabilizou-se a partir dos 35 anos de idade, em um valor de aproximadamente 0,6.

\section{DYNAMIC OF STEM TAPER AND WOOD PRODUCTION IN Araucaria angustifolia PLANTATIONS}

ABSTRACT: The research aimed to evaluate the evolution of stem taper and wood assortment in plantations of Araucaria angustifolia. The data came from 30 sampled trees in plantations established between the decades of 1940-1960 in Irati National Forest, Parana State, Brazil. The trees were subjected to the technique of complete stem analysis that allows reconstitution of the entire past growth. The data generated allowed the obtaintion of diameter at different heights at various ages. The mean stem profile by age was obtained from taper functions and cubic splines functions were used to evaluate the evolution of wood assortment by age classes. We also conducted studies on the stem taper dynamics with the use of form factors. The results were presented with the mean of all trees and grouping them into two site classes, when the trees are 50 years old they reach an average volume of $1.20 \mathrm{~m}^{3}$, of which $14 \%$ could be used for lamination, $66.2 \%$ for sawmill 2 , $15.9 \%$ for sawmill I, 3.7\% for pulpwood and only $0.3 \%$ would be residuals. In this same age the sites I and II had mean total volume of $1.94 \mathrm{~m}^{3}$ and $0.57 \mathrm{~m}^{3}$, respectively. The $5^{\text {th }}$ degree polynomial function adjusted by age classes allowed to infer that stem tapering improves with age, with the stem becoming more cylindrical. This same trend can be established on the form factor, which practically stabilized after the 35 years of age, at a value of about 0.6 . 


\section{INTRODUÇÃO}

A Araucaria angustifolia é uma espécie nativa conhecida como Pinheiro-do-Paraná e possui grande valor paisagístico e econômico. Sua madeira é própria para forros, molduras, ripas, caixotaria, brinquedos, construção civil, laminação, entre outros produtos (LORENZI, 1992). Produz celulose de fibras longas, que gera um papel de excelente qualidade.

A Araucária é uma árvore alta, de aspecto original e contrastante com as demais árvores do sul do Brasil e pode atingir 20 a 50 metros de altura e até 2 metros de diâmetro. $O$ tronco é bastante cilíndrico, reto e, raras vezes, ramificado em dois ou mais fustes, casca grossa e resinosa, cuja superfície externa se desprende em placas cinzento-escuras (REITZ; KLEIN, 1966).

Para proporcionar o uso múltiplo do tronco de uma árvore, faz-se necessário o conhecimento do afilamento do tronco, do volume e dimensão dos seus sortimentos, possibilitando, assim, o planejamento e o estudo da viabilidade econômica de um empreendimento florestal (PEREIRA et al., 2005).

afilamento do tronco é definido como sendo o decréscimo em diâmetro da base de um tronco para o topo. Pode variar com a espécie ou material genético, com o espaçamento inicial e com a prática de desbastes, além da capacidade produtiva do lugar, dentre muitos outros fatores. Conforme Baldwin et al. (2000), é esperado que árvores plantadas em maiores espaçamentos iniciais apresentem fustes mais cônicos, em comparação com árvores sob espaçamentos mais reduzidos.

Figueiredo Filho (199I) mencionou que a qualidade do sítio afeta a forma do tronco. Em sítios de baixa capacidade produtiva, as árvores, normalmente, têm maior conicidade ou formas indesejáveis. Nesses sítios, o crescimento em altura para árvores de mesmo diâmetro é menor e, como consequência, o fuste é mais afilado. Além disso, a distribuição do crescimento em diâmetro sobre o tronco varia consideravelmente com o sítio. Nos sítios produtivos, o crescimento é mais concentrado na parte da copa, enquanto nos sítios pobres, o crescimento tende a ser uniformemente distribuído no tronco.

As árvores que crescem isoladas mantêm uma copa proporcionalmente mais comprida e o tronco assume, então, uma forte conicidade. Esse fato pode também ser observado nas árvores que crescem em povoamentos, mas que têm, ainda, um crescimento livre, característico das árvores dominantes que, normalmente, apresentam uma copa mais vigorosa (FIGUEIREDO FILHO, I99I).
O aproveitamento de uma árvore deve ser feito de maneira que proporcione o maior retorno financeiro. Assim, quando uma mesma árvore tem diversos usos finais, o seu valor agregado é maior, pois alcança preços diferentes no mercado (MACHADO et al., 2004).

A aplicação de funções de afilamento é um poderoso instrumento para avaliar biológica e economicamente o maciço florestal e a resposta às práticas de manejo executadas, já que permitem valorar de maneira detalhada quanto renderá o povoamento florestal (FISCHER et al., 200I). Essas funções, decorrentes de sua flexibilidade, possibilitam uma estratificação, ou seja, a quantificação dos múltiplos produtos existentes por meio de dimensões préestabelecidas (QUEIROZ et al., 2008).

Segundo Prodan et al. (1997), modelo de afilamento é uma importante ferramenta estatística de uso corrente na determinação de volumes de árvores e toras, pois permite ao usuário estimar três características básicas das árvores: diâmetro em qualquer ponto do fuste, altura do fuste onde se encontra um determinado diâmetro e volumes entre pontos quaisquer do fuste.

Muitas pesquisas têm sido realizadas com o objetivo de descrever, de forma otimizada, a classificação dos fustes segundo sua qualidade, suas dimensões e suas possibilidades de utilização, garantindo, além da classificação física, melhor remuneração da madeira, com a destinação de toras de diversas bitolas ao mercado específico (SOUZA et al., 2008). O conhecimento do sortimento em dado momento da floresta, bem como de sua evolução ao longo do tempo é fundamental para fins de planejamento de uso da matéria-prima produzida, sendo, também, imprescindível na modelagem do crescimento e da produção em classes de diâmetro.

O sortimento é o seccionamento da árvore pelas dimensões diâmetro e comprimento das toras, gerando estimativas de multiprodutos que permitem um melhor planejamento na busca de um maior retorno financeiro. Quanto maior o diâmetro e os comprimentos, maiores as dimensões das peças resultantes, consequentemente, podem gerar maiores preços no mercado.

Figueiredo Filho (1991) estudou os efeitos da resinagem no crescimento em diâmetro, altura e volume de 44 árvores de Pinus elliottii, onde metade foi resinada. A resinagem não acarretou alterações na forma das árvores, mas acarretou mudanças no sortimento volumétrico das resinadas. Foram usadas funções splines cúbicas para determinar a evolução do sortimento, sendo possível visualizar as diferenças entre as resinadas e não-resinadas. Dessa forma, o autor pode concluir 
que, ao final do período estudado, as árvores resinadas produziram menores quantidades de volume total.

Friedl (1989) analisou a dinâmica da forma dos fustes de árvores de Araucaria angustifolia, avaliando o efeito da idade, sítio e posição sociológica na forma dos fustes. $O$ autor detectou uma forte influência da idade sobre a forma, sendo que esta melhorou com a idade.

Burgeretal. (1979)avaliaramodesenvolvimento da forma de Araucaria angustifolia com dados de análise de tronco de 52 árvores, com média de 28 anos de idade. Concluíram que a forma geométrica das árvores melhora constantemente com a idade e na juventude a forma de toda a árvore é semelhante a um parabolóide, e com o decorrer dos anos essa forma muda para neilóide na base e parabolóide no restante do tronco.

Santos (2006) pesquisou a influência dos fatores edáficos no crescimento e produção de diferentes procedências de Araucária, na Fazenda Experimental de Rio Negro da UFPR. Concluiu que existe um padrão de crescimento diferente para as árvores dominantes e dominadas, tendo observado que ocorre uma estagnação do crescimento diamétrico na base das dominadas.

Em decorrência da importância do tema, neste trabalho, objetivou-se avaliar a evolução da forma dos troncos e do sortimento em um plantio de Araucaria angustifolia.

\section{MATERIAL E MÉTODOS}

\section{Localização da área de estudo}

O estudo foi realizado em plantios de Araucaria angustifolia estabelecidos na Floresta Nacional de Irati (FLONA de Irati), situada no segundo planalto paranaense, no âmbito dos municípios de Fernandes Pinheiro e Teixeira Soares, integrantes da microrregião Colonial de Irati, região Centro-Sul do estado do Paraná (MAZZA et al., 2005).

A FLONA se localiza entre as coordenadas $E=538.217,9 \mathrm{~m}$ a $E=549.784,5 \mathrm{~m}$ e $\mathrm{N}=7.188 .444,2 \mathrm{~m}$ a $\mathrm{N}=7.201 .876,4 \mathrm{~m}$ do sistema UTM/Fuso 22. A altitude média do local é de 885 metros acima do nível médio dos mares (POTTKER, 20I2). Segundo a classificação climática de Köppen, a região apresenta clima do tipo $\mathrm{Cfb}$ com geadas frequentes no inverno. A temperatura média máxima é de $24,2^{\circ} \mathrm{C}$ e a média mínima de II,0 C. A precipitação média mensal de 193,97 mm (FIGUEIREDO FILHO et al., 2006b).

\section{Amostra}

A Floresta Nacional de Irati dispõe de vários talhões com plantios de Araucaria angustifolia. A maioria dos talhões foi estabelecida nas décadas de 1940, 1950 e 1960 e a quase totalidade está, atualmente, com mais de 40 anos de idade (FIGUEIREDO FILHO et al., 2006a). Nesses talhões foram amostradas 30 árvores, representando as várias classes de diâmetro e as várias idades existentes (Tabela I). De cada árvore, foram retirados discos (fatias) nas alturas absolutas 0, I e I,3 m (DAP) e nas alturas relativas de 15, 25, 35,..., 95\% da altura total. A técnica de análise de tronco completa (ANATRO) foi então utilizada para recuperar o crescimento passado em diâmetro, altura total, volume, perfil do tronco em qualquer idade, dentre outras.

TABELA I Distribuição da amostra em classes de DAP e de idade $(\mathrm{cm})$.

TABLE I Distribution of the sample in dbh and age classes (cm).

\begin{tabular}{|c|c|c|c|c|c|c|c|c|}
\hline \multirow{2}{*}{$\begin{array}{c}\text { Classes } \\
\text { de DAP } \\
(\mathrm{cm})\end{array}$} & \multicolumn{8}{|c|}{ Classes de Idade (anos) } \\
\hline & 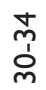 & $\begin{array}{l}\text { m } \\
\text { ஸे } \\
\text { n}\end{array}$ & $\begin{array}{l}\text { ষ } \\
\text { 워 }\end{array}$ & $\begin{array}{l}\text { f̛ } \\
\text { ஸे }\end{array}$ & $\begin{array}{l}\text { ஸे } \\
\text { ㅇํ }\end{array}$ & 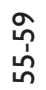 & $\begin{array}{l}\text { 우 } \\
\text { ơ }\end{array}$ & Total \\
\hline $15-19,9$ & - & - & I & - & - & 1 & - & 2 \\
\hline $20-24,9$ & - & - & - & 3 & 2 & - & - & 5 \\
\hline $25-29,9$ & - & - & I & I & I & 1 & - & 4 \\
\hline $30-34,9$ & 2 & - & - & I & - & - & I & 4 \\
\hline $35-39,9$ & - & - & - & I & I & 4 & - & 6 \\
\hline $40-44,9$ & - & - & - & I & 2 & 1 & - & 4 \\
\hline $45-49,9$ & - & - & - & I & I & - & - & 2 \\
\hline $50-54,9$ & - & - & I & - & 1 & 1 & - & 3 \\
\hline Total & 2 & 0 & 3 & 8 & 8 & 8 & I & 30 \\
\hline
\end{tabular}

\section{Análise de tronco completa}

Os discos coletados ao longo do tronco foram lixados após secagem e em cada um deles traçados 4 raios onde os anéis anuais de crescimento foram medidos, obtendo-se os diâmetros (sem casca) de cada idade. A porção final das alturas de cada idade foi estimada com base na semelhança de triângulos.

Os parâmetros dendrométricos de cada árvore foram calculados com o suplemento Florexel. Para este trabalho específico, as variáveis de interesse foram o volume total com casca, a altura total, o DAP com casca e os diâmetros sem casca nas várias alturas e nas várias idades. 


\section{Estimativa dos diâmetros com casca ao longo} do tronco nas várias idades

A ANATRO permite determinar os diâmetros com casca, apenas para a idade em que a árvore foi derrubada. Como o sortimento de uma árvore é realizado com base no diâmetro com casca na ponta fina das toras, ajustou-se o modelo matemático 1 utilizado por Schneider (1978) para estimar os diâmetros com casca ao longo do tronco e, assim, gerar os perfis com casca nas várias idades. No modelo $\ln =$ logaritmo neperiano; $d_{c c}=$ diâmetro com casca $(\mathrm{cm})$ estimado na altura $h_{i}(\mathrm{~m}) ; d_{s c}=$ diâmetro sem casca $(\mathrm{cm})$ medido na ANATRO na altura $h_{i}(\mathrm{~m}) ; h=$ altura total $(\mathrm{m}) ; \mathrm{I}=$ idade (anos); $b_{0}, b_{1}, b_{2}=$ coeficientes estimados por regressão.

$\ln d_{c c}=b_{0}+b_{1} \ln \left(d_{s c}\right)+b_{2} \ln (h l)$

\section{Agrupamento da amostra por sítio}

Os dados de crescimento em altura de todas as árvores foram plotados em um gráfico, a fim de se analisar o padrão de crescimento das árvores. As árvores posicionadas acima da curva de tendência média foram consideradas como sendo de um sítio de melhor produção (Sítio I) e as árvores cujas curvas estavam abaixo foram agrupadas como sendo de um sítio de menor produção (Sítio II).

\section{Evolução do sortimento}

A partir dos diâmetros com casca estimados ao longo do tronco, nas idades 10, 15, 20, 25, 30, 35, 40, 45 e 50 anos, funções splines cúbicas foram ajustadas por interpolação para cada perfil do tronco, conforme usado por Figueiredo Filho (1991). Apenas algumas árvores possuíam idade acima de 50 anos, portanto o sortimento foi avaliado somente até essa idade. É importante ressaltar que quando se tem diâmetros em vários pontos ao longo do tronco, funções splines cúbicas ajustadas por interpolação podem estimar volumes equiparados aos volumes ditos reais obtidos pelos métodos tradicionais de cubagem, como Smalian, Huber, etc. (BIGING, 1988; FIGUEIREDO FILHO et al., 2000; GOULDING, 1979).

A partir desses ajustes, determinou-se $\circ$ sortimento para cada idade para finalmente, avaliar a evolução do sortimento. As classes de sortimentos foram definidas, a partir de informações pessoais obtidas junto à STCP ENGENHARIA DE PROJETOS LTDA e estão de acordo com as exigências das indústrias que operam com matéria prima de plantios florestais na região (Tabela 2).

O sortimento do plantio foi avaliado para três grupos diferentes: incluindo toda a amostra de árvores, árvores pertencentes ao sítio I e árvores do sítio II.

TABELA 2 Classes de Sortimento.

TABLE 2 Assortment classes.

\begin{tabular}{lcc}
\hline Destinação & $\begin{array}{c}\text { Diâmetro com casca } \\
(\mathrm{cm})\end{array}$ & $\begin{array}{c}\text { Comprimento das } \\
\text { toras }(\mathrm{m})\end{array}$ \\
\hline Resíduos & $<8$ & 2,4 \\
Celulose & $\geq 8<16$ & 2,4 \\
serraria I & $\geq 16<23$ & 3,1 \\
serraria 2 & $\geq 23<35$ & 3,1 \\
Laminação & $\geq 35$ & 3,1 \\
\hline
\end{tabular}

\section{Evolução do afilamento das árvores}

O polinômio de $5^{\circ}$ grau (SCHÖPFER, 1966) foi ajustado para as várias classes de idades, a fim de avaliar a evolução do afilamento das árvores. O fator de forma também foi empregado para o mesmo fim, tendo sido calculados nas várias idades, utilizando-os para gerar uma equação pelo método de seleção de variáveis "Stepwise". Como variáveis de entrada foram testadas a Idade, 1/ Idade, Idade ${ }^{2}$, Idade ${ }^{3}$ e In (Idade). A equação foi utilizada para estimar os fatores de forma médios, por idade.

\section{RESULTADOS E DISCUSSÃO}

\section{Estimativa dos diâmetros com casca ao longo do tronco nas várias idades}

A seguir pode-se observar a equação 2 ajustada para estimar os diâmetros com casca e suas respectivas estatísticas.

$$
\begin{aligned}
& \operatorname{lnd}_{\mathrm{cc}}=-1,0718+1,2161 \ln \left(\mathrm{d}_{\mathrm{sc})}+0,0311 \ln (\mathrm{hl})\right. \\
& \mathrm{R}_{\text {adj }}^{2}=0,833 \\
& \mathrm{~S}_{\mathrm{yx}}=20,2 \%
\end{aligned}
$$

\section{Evolução do sortimento médio por árvore}

Na Figura I, observa-se a evolução do número de toras médio. Cada árvore apresenta em média 6,6 toras aos 50 anos, divididas entre os sortimentos. $O$ número de toras para celulose é maior aos 20 anos do povoamento com, aproximadamente, 2 toras por árvore, estando sempre presente nas idades seguintes, mas em 
menores quantidades. As toras para serraria I aparecem aos 15 anos e atingem em média 2,23 toras na idade 30 anos, depois diminuem, em razão do surgimento de diâmetros adequados para serraria 2. As toras para laminação só surgiram, a partir dos 35 anos, com cerca de uma tora por árvore.

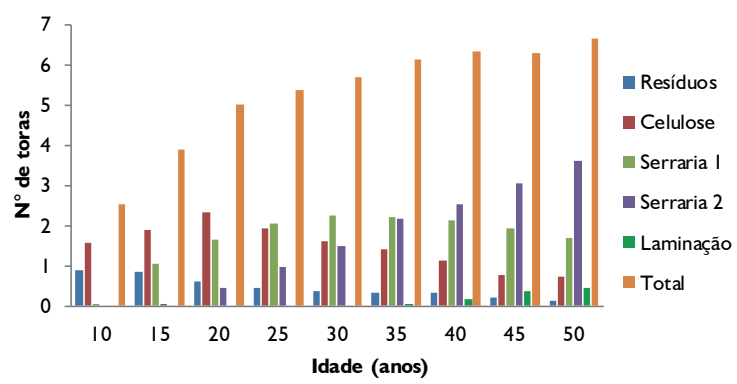

FIGURA I Evolução do número de toras médio por árvore para cada sortimento considerando toda a amostra.

FIGURE I Mean number of logs evolution for each tree assortment considering all sampled trees.

A evolução do sortimento do volume médio por árvore para o povoamento, pode ser observado na Figura 2. O volume médio atingido por árvore aos 50 anos foi de I,20 $\mathrm{m}^{3}$. Nessa idade, o volume destinado para serraria 2 representa $66,2 \%$ do volume total do povoamento, 15,9\% para serraria I, I4 \% para laminação, 3,7\% para celulose e apenas $0,3 \%$ de resíduos.

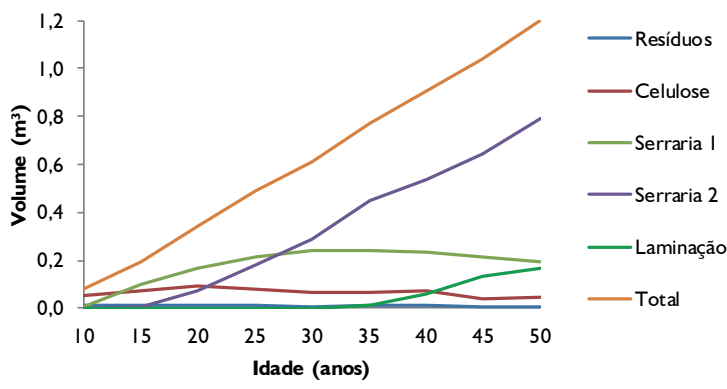

FIGURA 2 Evolução do sortimento do volume médio por árvore.

FIGURE 2 Mean volume assortment evolution per tree.

Figueiredo Filho (199I) encontrou para um plantio de Pinus elliottii, em Telêmaco Borba, estado do Paraná, um volume médio por árvore de $0,345 \mathrm{~m}^{3}$ aos 15 anos e, nessa idade, $34 \%$ da madeira era adequada para celulose e $57 \%$ para serraria Todavia, aos 23 anos, o volume médio evoluiu para $0,727 \mathrm{~m}^{3}$, dos quais, $48 \%$ poderiam ser laminados.
Santos (2006) estudou o crescimento de um plantio de Araucaria angustifolia, onde encontrou um

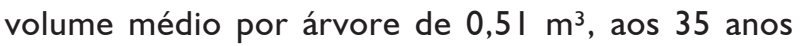
de idade.

\section{Evolução dos sortimentos para os sítios I e II}

O sítio I, considerado como de melhor qualidade, apresenta uma média de 9,6 toras por árvore aos 50 anos, enquanto que o sítio II apresenta uma média de 4,3 toras por árvore, nessa mesma idade, como se mostra na Figura 3. Para o sítio II até a idade analisada não havia ainda material para ser laminado.
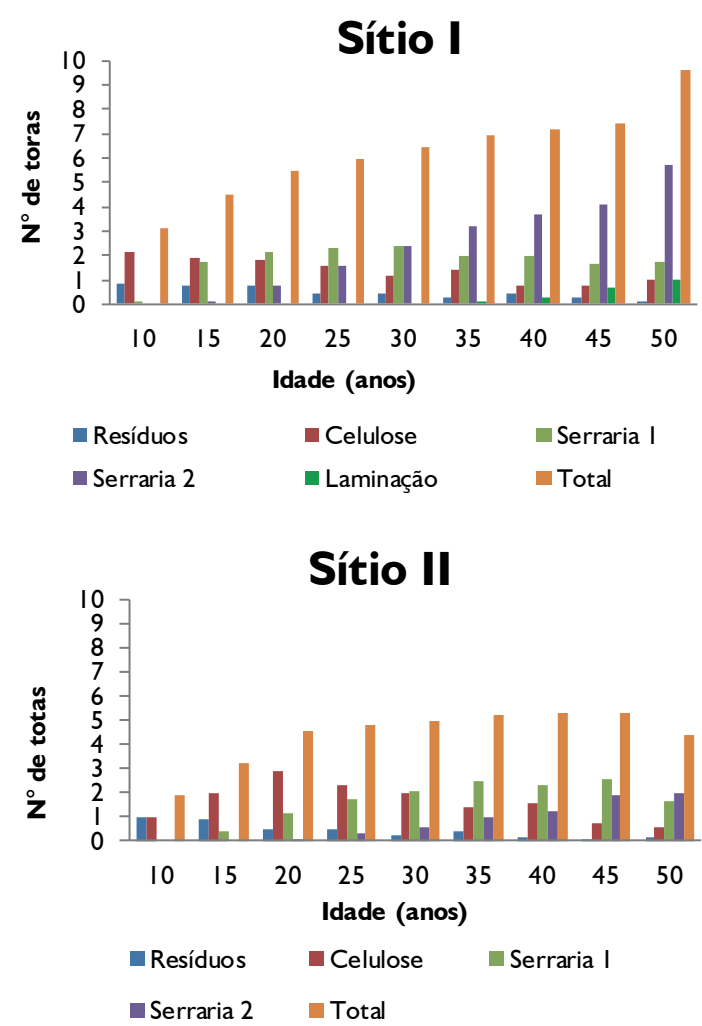

FIGURA 3 Número de toras médio por árvore para cada sortimento nos sítios I e II.

FIGURE 3 Mean number of logs for tree for each assortment in site I and II.

Pode-se observar, na Figura 4, que aos 10 anos de idade as árvores do sítio I têm 7I,4\% de volume $\left(\mathrm{m}^{3}\right)$ para celulose, 10,7\% para serraria I e 17,9\% de resíduos. Já, o sítio II aos 10 anos ainda não possui madeira para serraria $I$, sendo $73,4 \%$ de volume para celulose e $26,6 \%$ de resíduos. $O$ volume para serraria I surge apenas aos I5 anos de idade, representando 31, I\% do total. 
Madeira para serraria 2 aparece no sítio I aos 15 anos de idade e, a partir dos 30 anos, participa com mais de $50 \%$ do volume total. Já, para o sítio II, esse tipo de sortimento somente aparece a partir dos 20 anos e só passa a representar mais que a metade do volume total aos 45 anos.

O volume para celulose tem sua maior participação aos 10 anos para ambos os sítios, diminuindo, gradativamente, com 0 avanço da idade. No sítio I, esse volume passa de $71,4 \%$ aos 10 anos para $27,1 \%$ aos 15 anos. No sítio II, o decréscimo do volume de celulose é mais lento, representando ainda $45,5 \%$ do volume total aos 20 anos.

Somente aos 35 anos, o sítio I produz madeira para laminação, representando $2,4 \%$ do total nesta idade e $19,7 \%$ aos 50 anos, enquanto que o sítio II não produz madeira para laminação até a idade de 50 anos. Isso é uma informação relevante para o manejo da espécie. O sítio II apresenta maior volume para celulose e serraria $I$ e isso mostra que as árvores pertencentes a esse sítio possuem um desenvolvimento mais lento que no sítio I, exigindo bem mais tempo para se dispor de madeira para uso mais nobre e de maior valor comercial.
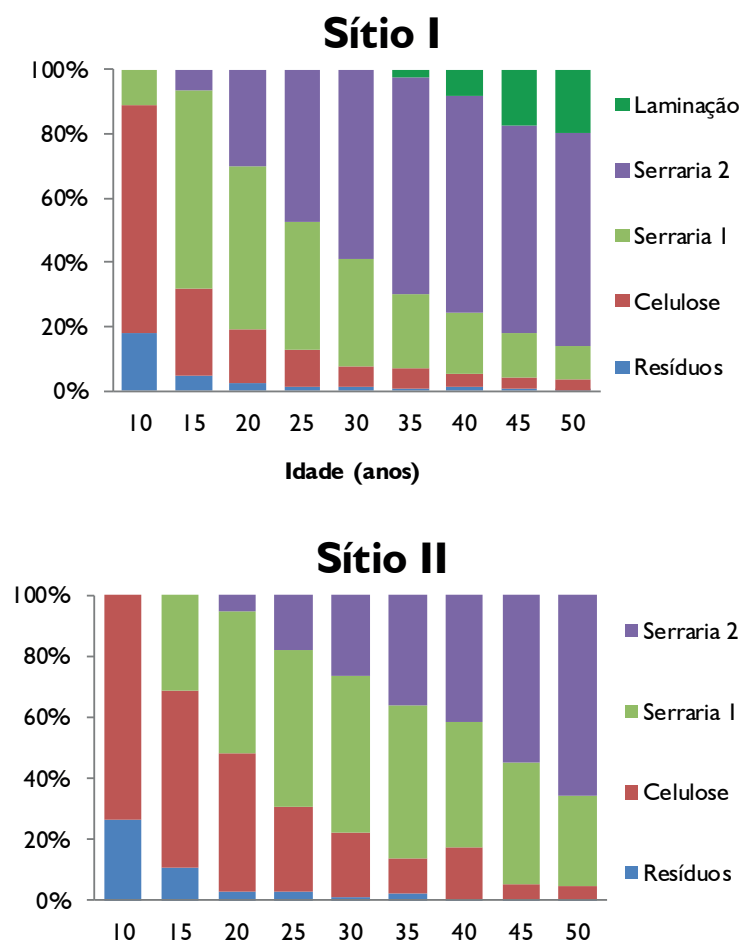

Idade (anos)

FIGURA 4 Evolução do sortimento médio por árvore e para os sítios I e II.

FIGURE 4 Mean assortment evolution per tree and for sites I and II.

\section{Evolução do afilamento}

Os resultados de ajustes do polinômio de $5^{\circ}$ grau para as várias classes de idades estão na Tabela 3 , assim como as respectivas estatítiscas do ajuste $\left(R^{2}{ }_{a d j}\right)$ e precisão ( $\left.\mathrm{S}_{y \mathrm{x}} \%\right)$. O erro padrão da estimativa diminui e o coeficiente de determinação aumentou com o avanço da idade, mostrando que a forma das árvores do povoamento tornou-se mais homogênea com o tempo.

TABELA 3 Coeficientes e estatísticas para os ajustes do polinômio de $5^{\circ}$ grau.

TABLE 3 Coefficients and statistics for the fittings of the $5^{\text {th }}$ degree polynomial.

\begin{tabular}{|c|c|c|c|c|c|c|c|c|}
\hline Idade & $b_{0}$ & $b_{1}$ & $b_{2}$ & $b_{3}$ & $\mathrm{~b}_{4}$ & & $R_{a d j}^{2}$ & $\mathrm{~S}_{y x} \%$ \\
\hline 10 & 1,6968 & $-4,|45|$ & 18,6240 & $-42,462$ & $42,|69|$ & $-15,875$ & 0,8862 & 219,27 \\
\hline 15 & $\mathrm{I}, 5038$ & 5474 & 17,1485 & 43,432 & 47,6209 & $-19,284$ &, 926 & 17,35 \\
\hline 20 & I,4227 & 3,2756 & $|5,3| \mid 4$ & 38,103 & $42,4 \mid I 5$ & -17 & $0,946 \mid$ & 3,68 \\
\hline 25 & 1,3929 & 72 & 17 & 43 & 49,2 & $-20,827$ & 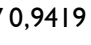 & 12,32 \\
\hline 30 & 1,3716 & ,7606 & 18,9526 & 48,191 & 55,0367 & $-23,37$ & 0,9347 & $7|2,3|$ \\
\hline 35 & 1,3513 & 4,225 I & 22,8452 & 59,563 & 68,7425 & $-29,11$ & 0,9455 & 10,94 \\
\hline 40 & 1,3337 & TO & 23,1 & (3) & 70 & $4-30,017$ & 70,94 & $|10,6|$ \\
\hline 45 & 1,3088 & ט, & 2 & וז, & 1 & 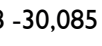 & 0,7 & 0,51 \\
\hline 50 & 1,2897 & 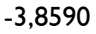 & 19,7 & $-0,002$ & וכון, מת & $-24,1$ & 8,2102 & 211,29 \\
\hline
\end{tabular}

$\mathrm{Na}$ Figura 5, observam-se as modificações da forma geométrica das árvores, durante seu crescimento. Pode-se observar que a forma das árvores varia conforme a idade, no início do plantio as árvores são mais afiladas, tornando-se mais cilíndricas com o aumento da idade, como esperado do ponto de vista dendrométrico. Os mesmos resultados foram observados por Burger et al. (1979), que estudaram o desenvolvimento da forma de Araucaria angustifolia e concluiu que na idade inicial a forma é parabolóide ao longo de todo o fuste, com o avanço da idade, a parte inferior torna-se neilóide, enquanto que a forma parabolóide na parte superior é cada vez mais acentuada.

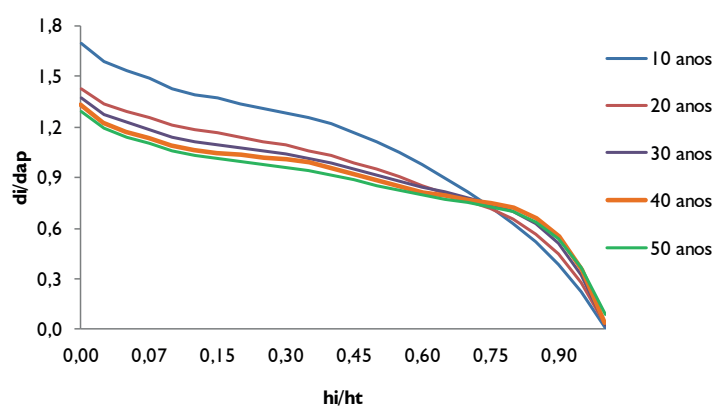

FIGURA 5 Evolução do afilamento para as árvores amostradas. FIGURE 5 Tapering evolution for sampled trees. 
O polinômio de $5^{\circ}$ grau não apresentou um bom ajuste para a idade inicial de 10 anos, com um erro padrão da estimativa alto $(19,3 \%)$ e o menor coeficiente de determinção de todas as idade $(0,8862)$. Isso ocorre, em razão da dispersão dos valores observados empregados no ajuste do modelo, como mostra a Figura 6. Aos 10 anos, os valores de di/dap estão muito dispersos ao longo da linha média. Pode-se observar que esses valores tornam-se mais homogêneos no decorrer do tempo, proporcionando uma melhor estimativa do modelo.

Essa melhora nos ajustes também foi observada por Friedl (1989), que estudou a dinâmica e prognose da forma dos fustes de araucária $\bigcirc$ autor associou a
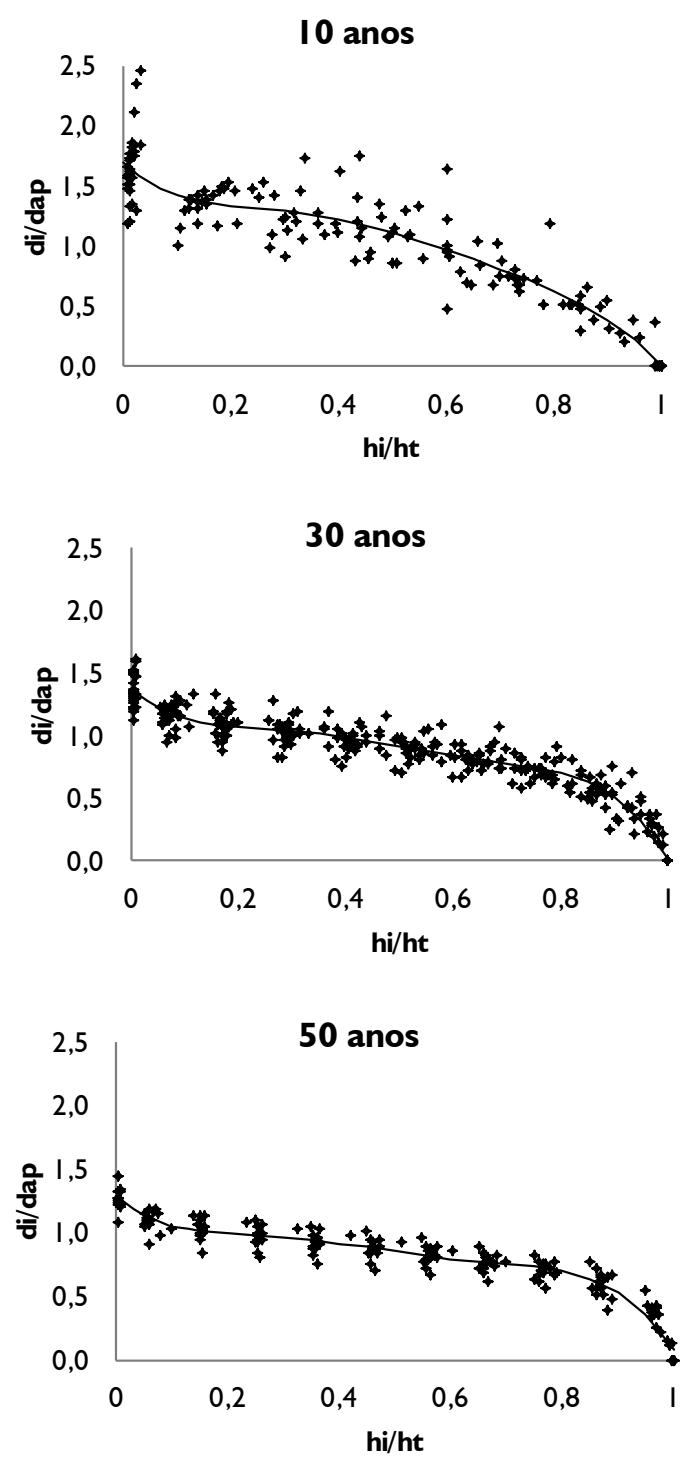

FIGURA 6 Distribuição dos valores observados sobre a curva de afilamento média ajustada.

FIGURE 6 Values observed distribution on mean tapering curve. melhora nos ajustes a uma melhor distribuição dos pontos amostrados no perfil ao aumentar a altura da árvore com a idade e à mudança que ocorre na árvore com a idade.

\section{Fator de Forma Comum}

As variáveis independentes escolhidas pelo método de seleção Stepwise formaram um modelo 3 que foi utilizado para estimar o fator de forma comum $\left(f_{1,3}\right)$, em que $I n=$ logaritmo neperiano, $I=I d a d e$ (anos), $b_{0}=-2,5705, b_{1}=8,762 \mathrm{I}, b_{2}=0,515819, b_{3}=-0,000001 \mathrm{I}$, $\mathrm{R}_{\mathrm{adj}}^{2}=0,8963, \mathrm{~S}_{\mathrm{yx}} \%=2 \mathrm{l}, 64$ :

$\ln f_{1,3}=b_{0}+b_{1}\left(\frac{1}{l}\right)+b_{2} \ln I+b_{3} I^{3}$

Foram estimados os fatores de forma para todas as árvores amostradas em todas as idades. Com a média dessas estimativas em cada idade, construiuse um gráfico com a evolução da forma dos troncos da Araucária (Figura 7).

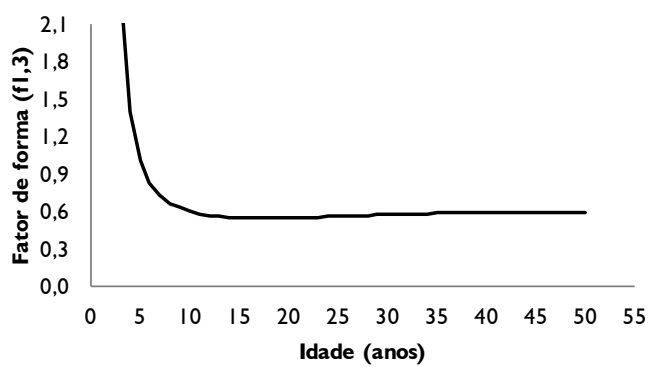

FIGURA 7 Evolução do fator de forma comum $\left(f_{1,3}\right)$. FIGURE 7 Form factor $\left(f_{1,3}\right)$ evolution.

Pode-se observar que, até os 4 anos de idade, o fator de forma é maior que um. Isso se deve ao fato de que, no início do seu desenvolvimento, o volume das árvores é maior que o volume do cilindro (medido com base no diâmetro à l,3 m do solo - DAP). A partir dos 4 anos, o fator de forma começa a diminuir, chegando ao menor valor na idade de I8anos $(0,58)$. Isso não significa que a forma geométrica da árvore esteja se tornando mais afilada, pois o fator de forma comum não representa diretamente a forma geométrica da árvore, mas, sim, o fator de redução para o cálculo do volume (BURGER et al., 1979). Após essa idade, o fator de forma aumenta, tornando-se praticamente constante, estabilizando-se com um valor em torno de 0,6, a partir dos 35 anos de 
idade. Constatou-se que o maior percentual de melhora da forma ocorreu entre as idades de 26 a 36 anos, cerca de 4,3\%. Nas demais idades, a melhora foi de em média de $2 \%$ a cada 10 anos. Esse comportamento traduz 0 fato de que o volume do tronco das árvores fica mais próximo ao de um cilindro com o aumento da idade.

\section{CONCLUSÕES}

Volumes para serraria são produzidos em plantios de araucária, a partir da idade de 10 anos para os sítios mais produtivos e apenas na idade 15 para sítios menos produtivos.

Em sítios mais produtivos, tem-se o volume para laminação somente aos 35 anos, tendo-se, aos 50 anos, para esse tipo de sortimento uma participação de 19,7\% do volume total produzido por árvore.

Aos 50 anos, ainda não se tem madeira para usos mais nobres (laminação) em sítios menos produtivos.

Como esperado do ponto de vista dendrométrico, com o avanço da idade, os troncos da araucária se tornaram mais cilíndricos e, praticamente, estabilizaram-se, a partir dos 35 anos, com um fator de forma em torno de 0,6.

\section{REFERÊNCIAS}

BALDWIN, V. C.; PETERSON, K. D.; CLARK, A.; FERGUSON, R. B.; STRUB, M. R.; BOWER, D. R. The effects of spacing and thinning on sand and characteristics of 38-yearold Loblolly pine. Forest Ecology and Management, Amsterdam, v. 137, p. 91-102, 2000.

BIGING, G. S. Estimating the accuracy of volume equations using taper equation of stem profile. Canadian Journal of Forest Research, Ottawa, v. 18, p. 1002-1007, 1988.

BURGER, D.; MACHADO, S. A.; HOSOKAWA, R. T. Estudo do desenvolvimento da forma de Araucaria angustifolia com relação á idade. In: ENCONTRO DA INTERNATIONAL UNION FOR FORESTRY RESEARCH ORGANIZATION, I., 1979, Curitiba. Anais... Curitiba: IUFRO, 1979. p. 320329.

FIGUEIREDO FILHO, A. Influência da resinagem no crescimento de Pinus elliottii Engelm. var. elliottii e sua avaliação econômica. 199I. I 38 f. Tese (Doutorado em Engenharia Florestal) - Universidade Federal do Paraná, Curitiba, 1991.

FIGUEIREDO FILHO, A.; DIAS, A. N.; WATZLAWICK, L. F. Inventário das florestas plantadas na floresta nacional de Irati, Estado do Paraná. Curitiba: UFPR, 2006a. 103 p.
FIGUEIREDO FILHO, A.; MACHADO, S. A.; CARNEIRO, M. R. A. Testing accuracy of log volume calculation procedures against water displacement technique (xylometer). Canadian Journal of Forest Research, Ottawa, v. 30, p. 990-997, 2000.

FIGUEIREDO FILHO, A.; SERPE, E. L.; PLODOWSKI, G.; SANTOS, D. F;; STEPKA, T. F; BECKER, M. Crescimento sazonal em diâmetro de 16 espécies de uma Floresta Ombrófila Mista na Floresta Nacional de Irati, Paraná, Brazil. In: CONGRESSO LATINOAMERICANO IUFRO, 2., 2006, La Serena. Anais... La Serena: IUFRO-INFOR, 2006b. v. I.

FISCHER, F.; SCOLFORO, J. R.; ACERBI, J. F. W.; MELLO, J. M.; MAESTRI, R. Exatidão dos modelos polinomiais não-segmentados e das razões entre volumes para representar o perfil do tronco de Pinus taeda. Ciência Florestal, Santa Maria, v. II, n. I, p. 167-I88, 200 I.

FRIEDL, R. A. Dinâmica e prognose da forma dos fustes em povoamentos plantados de Araucaria angustifolia (Bert.) O. Ktze. 1989. 167 f. Dissertação (Mestrado em Engenharia Florestal) - Universidade Federal do Paraná, Curitiba, 1989.

GOULDING, C. J. Cubic spline curves and calculation of volume sectionally measured trees. New Zealand Journal of Forestry Science, Rotorua, v. 9, n. I, p. 8999, 1979.

LORENZI, H. Árvores brasileiras: manual de identificação e cultivo de plantas arbóreas nativas do Brasil. São Paulo: Plantarum, 1992. 368 p.

MACHADO, S. A.; URBANO, E.; CONCEIÇÃO, M. B.; FIGUEIREDO FILHO, A.; FIGUEIREDO, D. J. Comparação de modelos de afilamento do tronco para diferentes idades e regimes de desbaste em plantações de Pinus oocarpa Schiede. Boletim de Pesquisa Florestal, Colombo, n. 48, p. 4I-64, 2004.

MAZZA, C. A. S.; MAZZA, M. C. M.; SANTOS, J. E. SIG aplicado à caracterização ambiental de uma unidade de conservação Floresta Nacional de Irati, Paraná. In: SIMPÓSIO BRASILEIRO DE SENSORIAMENTO REMOTO, 12., 2005, Goiânia. Anais... Goiânia: INPE, 2005. p. $225 \mathrm{I}-2258$.

PEREIRA, J. E. S.; ANSUJ, A. P.; MÜLLER, I.; AMADOR, J. P. Modelagem do volume do tronco do Eucalyptus grandis Hill ex. Maridem. In: SIMPÓSIO DE ENGENHARIA DE PRODUÇÃO, 12., 2005, Bauru. Anais... Bauru: SIMPEP, 2005.

POTTKER, G. S. Distribuição espacial de espécies da floresta ombrófila mista na Flona de Irati, Paraná. 20I2. 96 f. Dissertação (Mestrado em Ciências Florestais) Universidade Estadual do Centro-Oeste, Irati.

PRODAN, M.; PETERS, R.; COX, F.; REAL, P. Mensura florestal. San José: IICA, 1997. 586 p. 
QUEIROZ, D.; MACHADO, S. A.; FIGUEIREDO FILHO, A.; ARCE, J. E.; KOEHLER, H. S. Identidade de modelos em funções de afilamento para Mimosa scabrella Bentham em povoamentos nativos da região metropolitana de Curitiba, PR. Floresta, Curitiba, v. 38, n. 2, p. 339-349, abr./jun. 2008.

REITZ, R.; KLEIN, R. M. Araucariaceae. Itajaí: Herbário Barbosa Rodrigues, 1966. 29 p.

SANTOS, W. C. Análise de características dendrométricas e fatores edáficos no crescimento e produção de um povoamento de Araucaria angustifolia (Bert.) O. Ktze. 2006. I 25 f. Dissertação (Mestrado em Engenharia Florestal) - Universidade Federal do Paraná, Curitiba, 2006.
SCHNEIDER, P. R. Modelo de equação e tabelas para avaliar o peso de casca de acácia-negra, Acacia mearnsiide Wild. 1978. 149 f. Dissertação (Mestrado em Engenharia Florestal) - Universidade Federal do Paraná, Curitiba, 1978.

SCHOEPFER, W. Automatisierung des massem, sorten und wertberechnung stenender waldbestande schriftenreihe Bad. Koblenz: Wurtt-Forstl, 1966.

SOUZA, C. A. M.; CHASSOT, T.; FINGER, C. A. G.; SCHNEIDER, P. R.; FLEIG, F. D. Modelos de afilamento para o sortimento do fuste de Pinus taeda L. Ciência Rural, Santa Maria, v. 38, n. 9, p. 2506-25I I, dez. 2008. 